\title{
University credits, tuition free
}

$\mathrm{W}$

orld Health Day marked the launch of the world's first free, for-credit Universitylevel training portal, NextGenU.org. Spearheaded by Dr. Erica Frank, a professor at the University of British Columbia, Vancouver, NextGenU provides anyone, anywhere, access to university- and graduate-level courses in the health sciences, either for interest or for credit.

NextGenU joins the ranks of other portals offering massive open online courses (MOOCs) including Udacity, Coursera, and EdX. However, while other portals offer trainees certificates of course completion, all NextGenU courses are offered in partnership with organizations, including universities and professional societies, certified to give courses for credit. Frank says that NextGenU is "just like an away rotation, but you can do it anyplace you want to; you don't have to go to the institutions that are co-sponsoring it."

NextGenU is aimed at addressing the global shortage of health care providers, particularly in developing countries. Many physicians worldwide lack access to specialty training, but sharing through MOOCs breaks down these barriers. "Once we create a course for one person, it's infinitely scalable," says Frank.

The name, NextGenU, is derived from NextGenerationYou, a testament to their goal of educating the next generation.

NextGenU's initial courses focus on health and include emergency medicine, environmental health, and climate change and health. This health focus is logical because medical and public health schools are generally accustomed to having students receive credit for courses offered through other institutions, says Frank, who is the Canada Research Chair in Preventive Medicine and Population Health.

Currently, the portal offers three courses and another 130 are being developed, including ones in sustain-

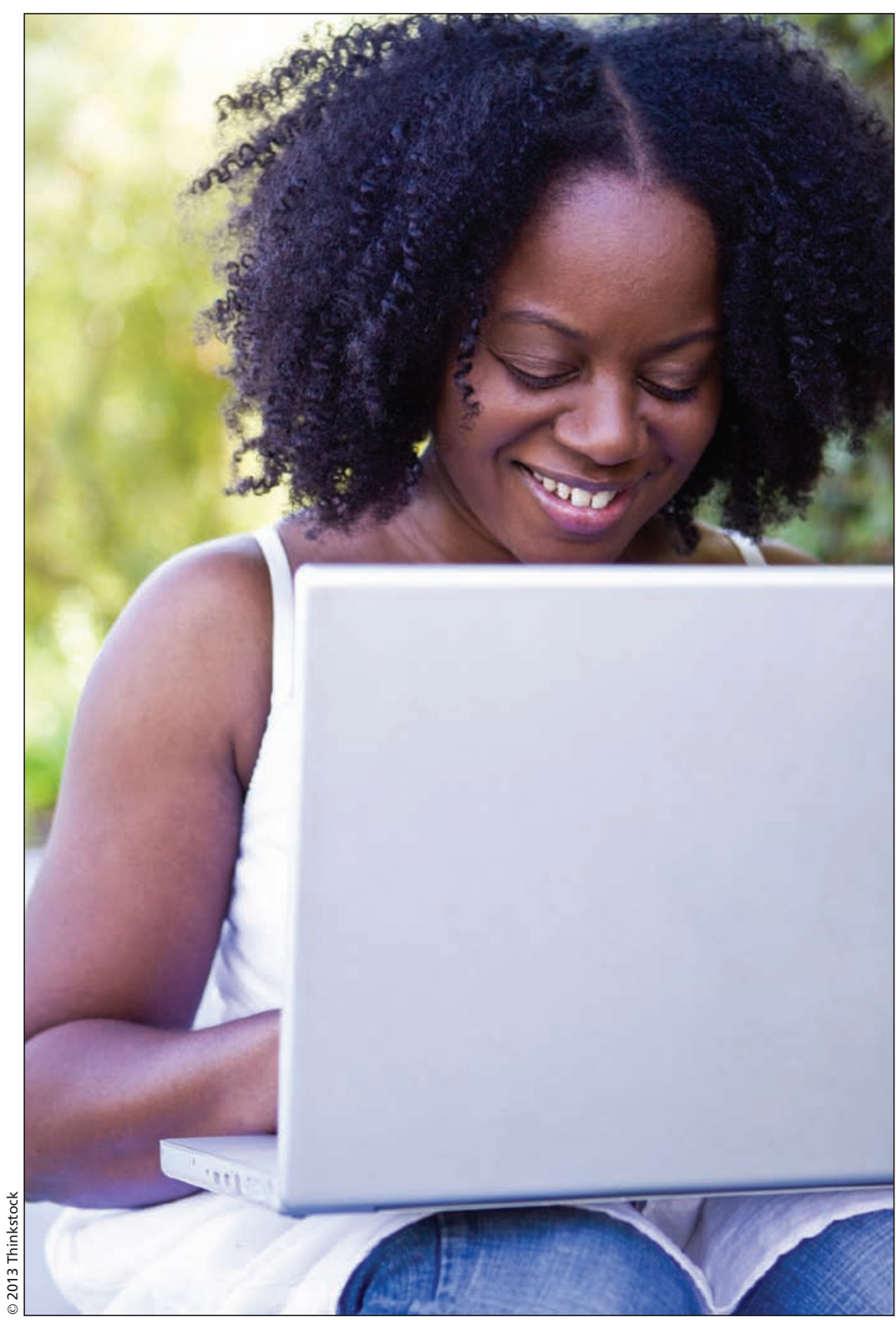

NextGenU is aimed at addressing the global shortage of health care providers, particularly in developing countries.

able urban design, introduction to legislation, sustainable waste management, cultural anthropology, human trafficking and field archeology. By the end of 2013, Frank says that "NextGenU expects to offer the equiv- alent of a masters' program in public health, with negotiations underway to have this become a degree through partner univerities in 2014."

Frank, a researcher in health sciences education, has been working to 
assemble and pilot course resources and strategies since 2001. In 2008, she launched Health Sciences Online, NextGenU's virtual health sciences library. The first students enrolled in NextGenU in the spring of 2012. At the time of the global launch April 7, NextGenU had 1015 registered trainees from 54 countries. The heaviest uptake thus far has been in North America, but there has been a great deal of interest internationally, says Frank.

While there are no admission requirements, in order to receive credit, a trainee must be registered at a recognized academic institution, or have obtained a prior degree. NextGenU trainees are assessed in four ways: self-assessment, peer-topeer assessment, mentor assessment and objective learning assessment (i.e., quizzes and final exam).

Critics of MOOCs cite low completion rates, poor learner support and difficulties in evaluation and accreditation as problems with the online learning model. In an email, Dr. Doug Holton, associate director of the Center for Teaching and Learning Excellence, Embry-Riddle Aeronautical University in Daytona Beach, Florida, writes that "Students in MOOCs are often left to support themselves, and the course materials may often consist of just video lectures and quizzes."

It's too early to know NextGenU's completion rates, but the model attempts to combat the problem by ensuring that trainees have the prerequisite knowledge to understand the course material.

In terms of learner support, NextGenU offers students extensive human interaction (work products, structured peer interactions and one-onone mentored activities), interactive computerized learning (interactive quizzes and word games), and both computerized and human assessments. The evaluation and accreditation of students is done by NextGenU's partnering organizations, which are already accredited by their governments and professional societies to give the credit for courses offered through NextGenU.

According to Holton, NextGenU's "excellent support from several collaborators and organizations" means it "should be able to overcome and adapt to any challenges."
NextGenU is an activity of the Ulrich and Ruth Frank Foundation for International Health, incorporated as a non-profit foundation in the United States. Their business model slogan, "grateful learners and inspired donors," invites grateful learners to donate money and/or time to the creation of additional training opportunities, or to serve as mentors. "Inspired donors" refers to the thousands of professionals who have freely posted learning resources online, course creators and staff who either volunteer their time or work for modest salaries (less than US\$25 per hour) and traditional donors, such as Grand Challenges Canada, the World Health Organization and the US Centers for Disease Control and Prevention. Erin Russell, CMAJ

CMAJ 2013. DOI:10.1503/cmaj.109-4484

Editor's note: Erica Frank MD is a member of the CMAJ Editorial Advisory Board. 